and 'lupus like' disease: association with antiphospholipid antibodies. Semin Arthritis Rheum 1987; 16: 253-9.

6 Burke C W. Adrenocortical insufficiency. Clin Endocrinol Metab 1985; 14: 947-75.

7 Asherson R A, Hughes G R V. Addison disease and primary antiphospholipid syndrome. Lancet 1989; ii: 874 .

Leucopenia after gold and sulphasalazine treatment

Sir: I read the interesting report by Bliddal and colleagues of three patients who developed leucopenia after both gold and sulphasalazine treatment.' HLA-DR3 as a marker for toxic reactions after treatment with gold or Dpenicillamine could not be shown. Patient 1 , however, was apparently a carrier of HLAB27. It is well known that female patients with rheumatoid arthritis, who are HLA-B27 positive, have a significantly higher risk for drug induced agranulocytosis, not only after treatment with levamisole ${ }^{2}{ }^{3}$ but also with other antirheumatic drugs. ${ }^{4}$ Thus under these conditions the possibility should be considered that in this patient, in the absence of HLAD3, HLA-B27 may be the risk indicator for her relapsing leucopenia.

K L SCHMIDT Department of Rheumatology and Physical Medicine University of Giessen University of Giessen
Ludwigstrasse 37-39 Ludwigstrasse 37-39 West Germany

1 Bliddal H, Eiberg B, Helin P, Sveigaard A. HLA types in patients with rheumatoid arthritis developing leucopenia after both gold and sulphasalazine treatment. Ann Rheum Dis 1989 48: $539-41$.

2 Schmidt K L, Mueller-Eckhardt C. Agranulocytosis, levamisole, and HLA-B27. Lancet 1977; ii: 85 .

3 Veys E M, Mielants H, Verbruggen G. Levamisole-induced adverse reactions in HLA-B27 positive rheumatoid arthritis. Lancet 1978; 148 .

4 Schmidt K L, Mueller-Eckhardt C, Breithaup H. HLA-B27, antinuclear antibodies and drug induced agranulocytosis. Klin Wochenschr 1978 56: 1189-91.

Sir: Thank you for your interesting comments on our article about HLA types of patients with leucopenia.

Our patients all had classical rheumatoid arthritis and none was positive for antinuclear antibodies. The observation in a small group of patients of HLA-B27 in just one case does not justify further conclusions.

Like many others we no longer use levamisole treatment for patients with rheumatoid arthritis.

HENNING BLIDDAL Department of Rheumatology Bispebjerg Hospital Denmark

Destructive spine lesions in ankylosing spondylitis

Sir: We read with interest the article by Aufdermaur entitled 'Pathogenesis of square bodies in ankylosing spondylitis'. ${ }^{1}$ In this case report of a patient with ankylosing spondylitis the author provided histopathological evidence to suggest a primary acute and chronic inflammatory lesion, resulting in destruction

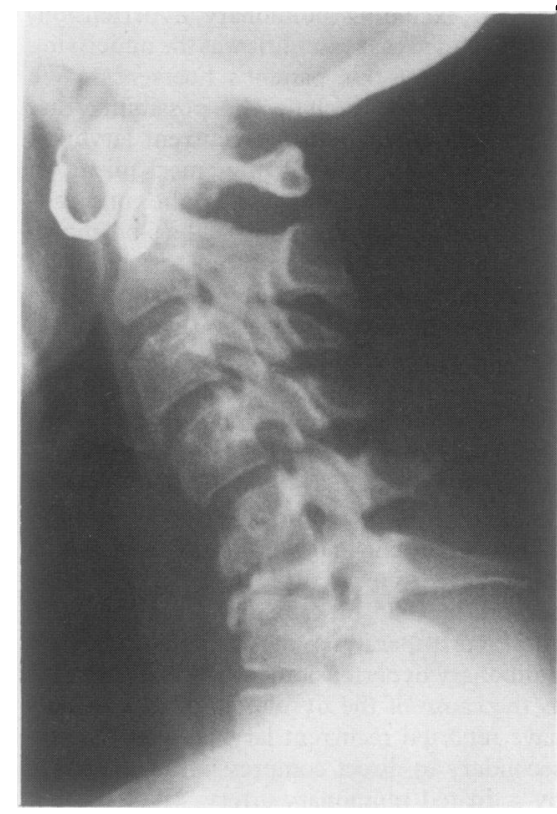

Severe destructive lesions of C6 and anterosuperior spondylitis of $\mathrm{C} 5$.

of the vertebral bodies, followed by new bone formation.

It might be interesting to recall our case of destructive cervical vertebral lesions showing ankylosing spondylitis in a 19 year old woman. During her disease of 18 months' duration she had inflammatory pain of the lumbar spine, sacroiliac joints, knees, and heels; radiographs showed bilateral sacroiliitis; HLA typing was A3, 9, B7, 12 and erythrocyte sedimentation rate $60 \mathrm{~mm} / \mathrm{lst} \mathrm{h}$. From the start of her disease she had had inflammatory pain of the cervical spine. Radiographs showed severe destructive lesions of the 6th cervical vertebra without discal lesions or cervical ankylosis, and a milder anterosuperior spondylitis of the 5th cervical vertebra (figure). There was no history of trauma. Surgical biopsy excluded a tumorous or infectious process. Spinal fusion (C4-7) was performed, and cervical pain disappeared with non-steroidal anti-inflammatory drugs. Histopathological examination of the 6th cervical vertebra biopsy specimen showed the absence of any inflammatory cells and the presence of spongiosa surrounded by fibrous tissue.

These findings are consistent with those of Aufdermaur; the inflammatory cervical pain, which was noted as an early symptom of the disease in our patient, might have been due to the inflammatory lesion of the vertebral body, and the present histopathological findings might represent the reparative stage with scar and new bone formation. It is noteworthy that this severe destructive cervical lesion was the first manifestation of ankylosing spondylitis in this patient.

$$
\begin{array}{r}
\text { A KAHAN } \\
\text { C J MENKES } \\
\text { Service de Rhumatologie A } \\
\text { Hôpital Cochin } \\
27 \text { rue du Faubourg Saint-Jacques } \\
75014 \text { Paris, France }
\end{array}
$$

1 Aufdermaur M. Pathogenesis of square bodies in ankylosing spondylitis. Ann Rheum Dis 1989, 48: 628-31.

2 Menkès C J, Kahan A, Feldmann J L, Vinh T. Spondylite cervicale destructrice. Manifestation Spondylice cervicale destructrice. Manifestation ankylosante. Presse Med 1983; 12: 227-9.
Low incidence of antinuclear antibodies in dermatomyositis with malignancy

Sir: In $1958 \mathrm{Walton}$ and Adams first classified 'polymyositis/dermatomyositis with malig nancy' as a distinct subset of polymyositis. Recent prospective controlled studies, however, cast doubt upon the increased incidence of malignancy in polymyositis/dermatomyositis. ${ }^{2}$ If the association of polymyositis dermatomyositis with malignancy happens by mere coincidence, serological features in these diseases with and without malignancy should not be different. The purpose of our preliminary study was to clarify this point in $\mathbf{3 6}$ patients with dermatomyositis.

Dermatomyositis was diagnosed according to the diagnostic criteria of Bohan and Peter. Thirty six patients were diagnosed as having pure adult dermatomyositis. These patients were further divided into two groups: 12 patients with dermatomyositis with malignancy (nine definite and three probable dermatomyositis) and 24 patients with dermatomyositis without malignancy (16 definite and eight probable dermatomyositis). Patients with dermatomyositis which overlapped with other connective tissue diseases were excluded from this analysis. Existence of malignancies was proved histologically by biopsy or necropsy, or both. Antinuclear antibodies were tested by indirect immunofluorescence with $\mathrm{HEp}_{2}$ cells (Kallstad, Chaska, Mn, USA) as substrates. Serum samples giving apparent fluorescence at a dilution of 1:40 were considered positive. The $\chi^{2}$ test was used for the statistical analysis.

Positive antinuclear antibodies were found in $13 / 24(54 \%)$ patients with dermatomyositis without malignancy, but they were found in only $2 / 12(17 \%)$ of those with malignancy $(\mathrm{p}<0.03)$. The low incidence of antinuclear antibodies in dermatomyositis with malignancy suggests the presence of a different serological background from that in the dermatomyositis without malignancy. This conclusion supports the view that a distinct subset of dermatomyositis exists—dermatomyositis with malignancy.

MASAHIKO NISHIKAI
AKIO SATO
Department of Internal Medicine
Second Tokyo National Hospital
Tokyo
Japan

I Walton J N, Adams R D. Polymyositis. Edinburgh: Churchill Livingstone, 1958

2 Manchul L A, Jin A, Pritchard K I, et al. The frequency of malignant neoplasms in patients frequency of malignant neoplasms in patients with polymyositis-dermatomyositis. A controlled

3 Lakhanpal S, Bunch T W, Ilstrup D M, Melton $\mathrm{L} J$ III. Polymyositis-dermatomyositis and malignant lesions. Does an associat
Mayo Clin Proc 1986; 61: 645-53.

4 Bohan A. Peter J B. Polymyositis and dermatoBohan A, Peter J B. Polymyositis and dermato-
myositis. N Engl f Med 1985; 292: 344-7, 403-7.

Inhibition of xanthine oxidase by allopurinol: its lack of effect on models of inflammation

Sir: In response to an article published in the Annals, entitled 'Inhibition of xanthine oxidase by allopurinol: A therapeutic option for ischaemia induced pathological processes?', we wish to report our findings on the effect of xanthine oxidase inhibition in models of joint 
and soft tissue inflammation. Recent evidence shows that endothelial cells subjected to immunological stimuli and ischaemia-reperfusion injury stimuli produce reactive oxygen species and that allopurinol and oxypurinol may be effective in reducing radical production and concomitant cell damage. ${ }^{24}$ As xanthine oxidase is considered to be one of the sources of these radicals its contribution to the progress of inflammation requires clarification. As the potential contribution of xanthine oxidase lies both in endothelial cell activation and in ischaemia-reperfusion injury we used models of inflammation in which an ischaemiareperfusion injury component had not previously been invoked (carrageenan induced air pouch inflammation and foot pad inflammation in the rat) and, in addition, a model of chronic persistent synovitis (adjuvant arthritis) in which the joint movement may lead to ischaemia-reperfusion injury as suggested by Blake et al.

Allopurinol $(18 \mathrm{mg} / \mathrm{kg}$ daily for five days before killing) in drinking water had no effect on acute inflammation induced by the subplantar injection of carrageenan in the rat paw. Similarly, allopurinol injected directly into rat air pouches $(10-250 \mathrm{mg} / \mathrm{kg}$ daily for three days before slaughter) had no effect on the acute (24 hour) or chronic (seven day) phases of carrageenan induced inflammation in this model as measured by total white cell count. Possibly, the use of a low molecular weight inhibitor such as allopurinol, with relatively fast renal clearance, resulted in incomplete inhibition of the enzyme for at least part of the duration of the experiment. We therefore used a more direct method to test the role of xanthine oxidase in inflammation by preventing the synthesis of active enzyme.

Tungsten mediated inhibition of molybdenum uptake produces a profound reduction in the activity of the enzyme xanthine oxidase, one of only three molybdenum dependent enzymes found in rats. ${ }^{67}$ We found that rats fed a diet low in molybdenum and supplemented with tungsten showed no change in the progress of carrageenan induced paw oedema when compared with rats fed a matched diet without tungsten supplementation and with defined molybdenum content. Similarly, there was no change in the progress or extent of Mycobacterium butyricum induced adjuvant arthritis (disease assessed by a joint scoring system and total body weight variation).

In conclusion, it seems unlikely that xanthine oxidase system plays a significant part in these models of inflammation.

We have previously proposed that the arthritic component of adjuvant disease may be exacerbated by episodes of ischaemiareperfusion injury and that this may be a feature of chronic synovitis in humans. ${ }^{5} \times$ Although these experiments do not support that hypothesis, they do not exclude other ischaemia-reperfusion mediated sources of injury or the effectiveness of trace amounts of residual xanthine oxidase. The immunological component of adjuvant disease is so powerful a drive in the progress of the arthritis that this is probably not the most sensitive of models for testing the contribution of a non-immunological variable. Ischaemia-reperfusion injury has not been proposed as a contributory factor in the other models of inflammation we used, but the involvement of endothelial cells in acute inflammation is well known and the aim of these experiments was to assess the contribution of xanthine oxidase in the endothelial cell response. Allopurinol is apparently ineffective in these models either because xanthine oxidase inhibition is unimportant or because a greater degree of inhibition is required.

R E ALLEN

A W D CLAXSON

D R BLAKE

C J MORRIS

The Inflammation Group

London Hospital Medical College

Whitechapel

London EI $2 A D$

Correspondence to: Professor Blake.

1 Puig J G, Mateos F A, Diaz V D. Inhibition of xanthine oxidase by allopurinol: A therapeutic option for ischaemia induced pathological processes? Ann Rheum Dis 1989; 48: 883-8.

2 Zweier J L, Kappusamy P, Lutty G A. Measurement of endothelial cell free radical generation. Evidence for a central mechanism of free radical Evidence for a central mechanism of free radical injury in postischemic tissue

3 Ratych R E, Chuknyiska R S, Bulkley G B. The primary localisation of free radical generation after anoxia-reoxygenation in isolated endothelial cells. Surgery 1987; 102: 122-31.

4 Gorog P, Pearson J D, Kakkar V V. Generation of reactive oxygen metabolites by phagocytosing endothelial cells. Atherosclerosis 1988; 72: 19-27.

5 Blake D R, Merry P, Unsworth J, et al. Hypoxicreperfusion injury in the inflamed human joint. Lancet 1989; i: 289-93.

6 Higgins E S, Richert D A, Westerfeld W W Molybdenum deficiency and tungstate inhibition Molybdenum deficiency and tungs

7 Johnson J L, Rajagopalan K V, Cohen H J. Molecular basis of the biological function of molybdenum. Effect of tungsten on xanthine oxidase and sulphite oxidase in the rat. $\mathcal{F} \mathrm{Bio}$ Chem 1974; 249: 859-66.

8 Woodruff T, Blake D R, Freeman J, Andrews F $J$, Salt $P$, Lunec $J$. Is chronic synovitis an example of reperfusion injury? Ann Rheum Dis 1986 ; 45: 608-11.

Genitorectal trichomonas invasion as (co)factor in pathogenesis of Behçet's syndrome

Sir: I read with interest the article by Teh et al describing severe proctitis with rectovaginal fistula in Behçet's syndrome.' Metronidazole was used in the treatment together with prednisolone and cephradine. Mouth ulcers disappeared after four days and other ulcerations healed after two months.

In my recent patient, a 29 year old woman with rectovaginal fistula and other manifestations fulfilling criteria for the diagnosis of Behçet's syndrome, rectal ulcerations were $2-3 \mathrm{~cm}$ around the fistula opening.

Mouth ulcers disappeared after seven days' treatment with metronidazole alone $(800 \mathrm{mg}$ twice daily) and ulcerations in other places after three weeks.

Treatment with metronidazole alone was given as Trichomonas vaginalis was found both in vaginal secretion and in smears from the mouth ulcers. Smears from the rectum, from the vicinity of the fistula opening, had microscopically proved infection of mucus with aflagellary forms of trichomonads. Of three cultures, only one was positive and this was for Trichomonas vaginalis. The fact that only one positive culture was obtained confirms observations that the existing culture media often give negative results with trichomonads from atypical locations.

Ten weeks after surgical closing of the fistula, regression of all symptoms of Behçet's syndrome occurred, pointing to a probable relation between genitorectal trichomonas invasion and Behçet's syndrome.

The report of Teh et al does not state whether detection of trichomonads had been attempted by culture method, and thus I presume that metronidazole was given because of its inhibitory effect on anaerobic bacteria. Its favourable effect on vaginal secretion and the regression of ulcers on mucous membranes might therefore be ascribed to the influence of metronidazole on unrecognised trichomoniasis. Immunology of trichomonads has proved the existence of common sensitisation, ${ }^{2}$ and thus I believe that primary genital and secondary rectal trichomoniasis in my patient caused maximal sensitisation and mouth ulcers, and elsewhere was an allergic phenomenon.

In the patient reported by Teh $e t a l$ and in similar cases of rectovaginal fistula the possibility of the existence of trichomoniasis and its secondary manifestations should be considered.

Direct cytopathogenic activity of parasites and their later toxic and allergic effects may play a part in the development of disease on mucous membranes, as well as on other tissues, which is found in Behcet's syndrome.

ŚUKRIJA KRVAVAC Women's Health Institute University and Medical Center Sarajevo, Yugoslavia

1 Teh L S, Green K A, O'Sullivan M M, Morris J S, Williams B D. Behcet's syndrome: severe proctitis with reciovaginal fistula formation. Ann Rheum Dis 1989; 48: 779-80.

2 Honigberg B M. Trichomonads of importance in human medicine. In: Kreier J P, ed. Parasitic protozoa. Vol 12. New York: Academic Press, protozoa. Vol 12.

Sir: There was no evidence of Trichomonas vaginalis infection in our patient, and appropriate cultures were all negative. She was treated with metronidazole to cover possible anaerobic infection.

$$
\begin{array}{r}
\text { L. S TEH } \\
\text { University Hospital of Wales } \\
\text { Heath Park } \\
\text { Cardiff } \\
\text { CF4 4XWW }
\end{array}
$$

\section{Rheumatological journals}

Sir: With the expansion of rheumatology over the past 50 years and the establishment of many new rheumatology centres in the United Kingdom, Europe, and elsewhere there must be a demand for back numbers and volumes of journals covering this exciting period, but I find it difficult to dispose of the following either for a nominal charge or for carriage:

Annals of the Rheumatic Diseases (1945-1982), all bound

Arthritis and Rheumatism (1958-1988)

Rheumatology (1981 to date)

British fournal of Rheumatology (1973 onwards), unbound.

It seems unlikely that I shall need them after this current year and I would welcome any offers from new centres in the United Kingdom or abroad. They take up a lot of shelving but it seems a pity to discard them, together with the British Medical Journal, the Fournal of the Royal Society of Medicine, and the Annals of Internal Medicine, if there is any current need for them.

E G L BYWATERS Long Acre 53 Burkes Road Beaconsfield Bucks HP9 IPW 